\title{
A Rare Association of Inflammatory Myofibroblastic Tumor of Maxilla and Idiopathic Orbital Inflammatory Disease
}

\author{
C Preetam, Rajeev Kumar, Kapil Sikka, Rakesh Kumar, Prashant Durgapal
}

\begin{abstract}
Inflammatory myofibroblastic tumor (pseudotumor) is a rare tumor belonging to the family of fibrous mesenchymal tumors. Though it usually involves lungs, but extrapulmonary site involvement, especially head and neck region is rare. In this paper, we are presenting a 26-year-old male patient, with inflammatory myofibroblastic tumor of maxilla, with a rare association with a prior history of idiopathic orbital inflammatory disease, treated medically. The patient was treated surgically with complete excision of the pathology from maxilla. This case report intents to review the controversies in management of this tumor and also to enlighten the possible association between the orbital and maxillary pseudotumor.
\end{abstract}

Keywords: Maxillary tumor, Inflammatory pseudotumor, Plasma cell granuloma, Pseudosarcomatous myofibroblastic lesions.

How to cite this article: Preetam C, Kumar R, Sikka K, Kumar R, Durgapal P. A Rare Association of Inflammatory Myofibroblastic Tumor of Maxilla and Idiopathic Orbital Inflammatory Disease. Clin R hinol An IntJ 2013;6(1):41-43.

\section{Source of support $\mathrm{Nil}$}

Conflict of interest: None declared

\section{INTRODUCTION}

Inflammatory myofibroblastic tumor (IM FT) or also known as inflammatory pseudotumor, plasma cell granuloma or pseudosarcomatous myofibroblastic lesion is a rare mesenchymal tumor, which usually involves the lungs. Numerous extrapulmonary sites have been described, like skin and soft tissue, spleen, heart, bladder, upper respiratory tract, mediastinum and kidney. ${ }^{1}$ The upper respiratory tract involving the larynx, trachea, oropharynx and nasopharynx accounts for $11 \%$ of extrapulmonary cases. The remaining sites in the head and neck account for less than $5 \%$ of cases, including orbit, paranasal sinus, skull base and temporal bone. ${ }^{2}$ The pathogenesis of this tumor is still an enigma and the rarity of this lesion worsens the matters further. Same concerns persist with the aspect of management of this tumor also. The probableinflammatory association of both the IM FT and orbital pseudotumor makes the coexistence of these lesions not just a coincidence, but a possible indicator to the common pathogenesis of these lesions. These diseases could well be a part of the spectrum of a same pathogenesis.

\section{CASE REPORT}

A 26-year-old male patient presented to us with complaints of persistent left-sided facial heaviness and occasional pain in left nasal cavity for 2 years. Patient also had an episode of self-limiting left-sided epistaxis. The clinical ENT examination did not reveal any obvious pathology excepting for left-sided minimal facial fullness. Patient was detected to have relative afferent papillary defect in the right eye al ong with a negative perception of light vision of the same eye. On retrospective evaluation, patient was detected to be a diagnosed case of orbital pseudotumor diagnosed in 2006. Patient then had developed a perception of light negative vision. Patient was treated with steroids and though patient had no visual improvement, but he had a plateau in disease progression. Patient was under regular follow-up in ophthal mology department of our institute with no further progression of the disease. Patient underwent a computed tomography of the paranasal sinuses, which reveal ed a soft tissue mass in the left maxillary sinus with a doubtful minimal anterolateral wall erosion (Fig.1). Retro-orbital soft tissue was also noted on the right side, which did not reveal any progression in comparison to previous scans. The patient underwent a sublabial biopsy which revealed the lesion to be an IM FT. The patient underwent a hemogram, serum analysis, autoimmune work-up, including A NCA, ANA, etc. and metastatic work-up with chest X-ray and ultrasound abdomen. The autoimmune and metastatic work-up were negative and thus after written informed consent, patient underwent a sublabial excision of the tumor with stripping of all maxillary sinus mucosa. No evidence of any bone erosion was noted during the surgery. The postoperative histopathology revealed the same tumor and no further
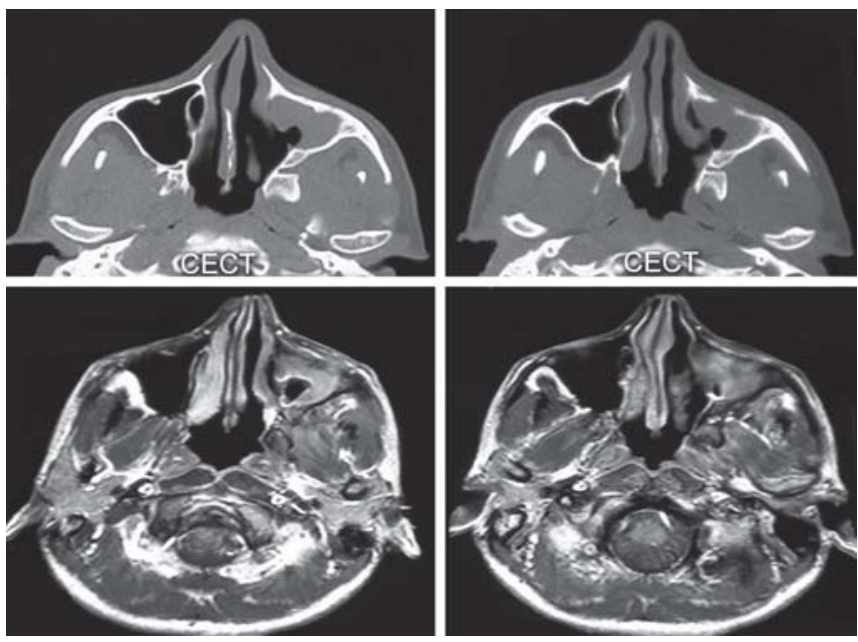

Fig. 1: Soft tissue mass in the left maxillary sinus with an anterolateral wall erosion 
treatment was administered to the patient. The patient was advised a close follow-up after explaining a possibility of even a late recurrence. The repeat radiology after 6 months shows the patient to be disease free. The histopathology exhibited plasma cells, lymphocytes and spindle-shaped proliferating fibroblasts. The tumor was positive for vimentin and desmin, suggesting a myofibroblastic origin. There was no evidence of granulomas or mitotic figures (Fig. 2).

\section{DISCUSSION}

IMFT was first described way back in 1939 by Brunn in lungs, but the term IMFT was initially proposed and the lesion originally described by Pettinato et $\mathrm{al}^{3}$ in 1990, in their study of 20 lesions of the lung. The most proper definition, formalized in the 1994 World Health Organization classification of soft tissue tumors, is IM FT, which refers to 'a tumor composed of differentiated myofibroblastic spindle cells usually accompanied by numerous plasma cells and/or lymphocytes' . ${ }^{4}$ These tumors are considered as tumors of intermediate biological potential with a tendency for local recurrence and $<5 \%$ chance of distant metastasis. ${ }^{5}$ The riddle of pathogenesis is far from solved with multiple hypotheses being proposed. It is believed to be inherited as a autosomal recessive or dominant with variable penetrance. ${ }^{6,7}$ Cytogenetic studies suggest a possible clonal rearrangement of $2 p 23$, involving $A L K$ receptor tyrosine kinase locus region, which have been detected in about $50 \%$ of cases. ${ }^{8,9}$ A nother important association is, IM FTs, particularly those in the spleen and liver, harbor the Epstein-Barr virus in spindle cells. ${ }^{10}$ In comparison the picture with orbital pseudotumor also is not too rosy. The exact pathogenesis is still not known, but a possible autoimmune origin with either viral, environmental or genetic factors acting as the trigger. ${ }^{11}$ The possible immune basis and response to steroids, along with histopathological features of inflammatory infiltrate mainly of mature lymphocytes admixed with plasma cells, neutrophils, eosinophils and macrophages makes the diagnosis immune/inflammatory in origin. This suggests a possible common trigger for both pathologies. A s the patient was diagnosed with IMFT, the primary point of concern was the possible mode of management and the prognosis expected in the patient. The literature clearly proves the IM FT to be a neoplastic lesion, but the lack of metastasis in cases involving head and neck made decisions of management more confusing. The options available were of surgery, steroid therapy, radiotherapy or chemotherapy. The neoplastic nature of pathology warranted a radical approach, but the slow growing nature (2 years), already $\mathrm{PL}$ negative vision in right eye, and good access made a conservative complete excision the best possible option. The steroid therapy and radiotherapy are usually limited to residual/recurrence or for intracranial lesions. Though trials of chemotherapy along with interferon were tried, but no consistent results are expected. ${ }^{12}$ So our decision of doing sublabial excision rather than a maxillectomy, with steroid therapy or radiotherapy as stand by treatment options in case of recurrence seemed very apt. B ut, the slow growing nature and local invasion demand along term follow-up with a possibility of late recurrence. O ur study though does not exactly characterize the pathogenesis; it just implicates the possible association of two tumors with very similar origin and possibly a varied spectrum of an common seed. L ongterm studies with a larger number are required before the association can be confirmed.

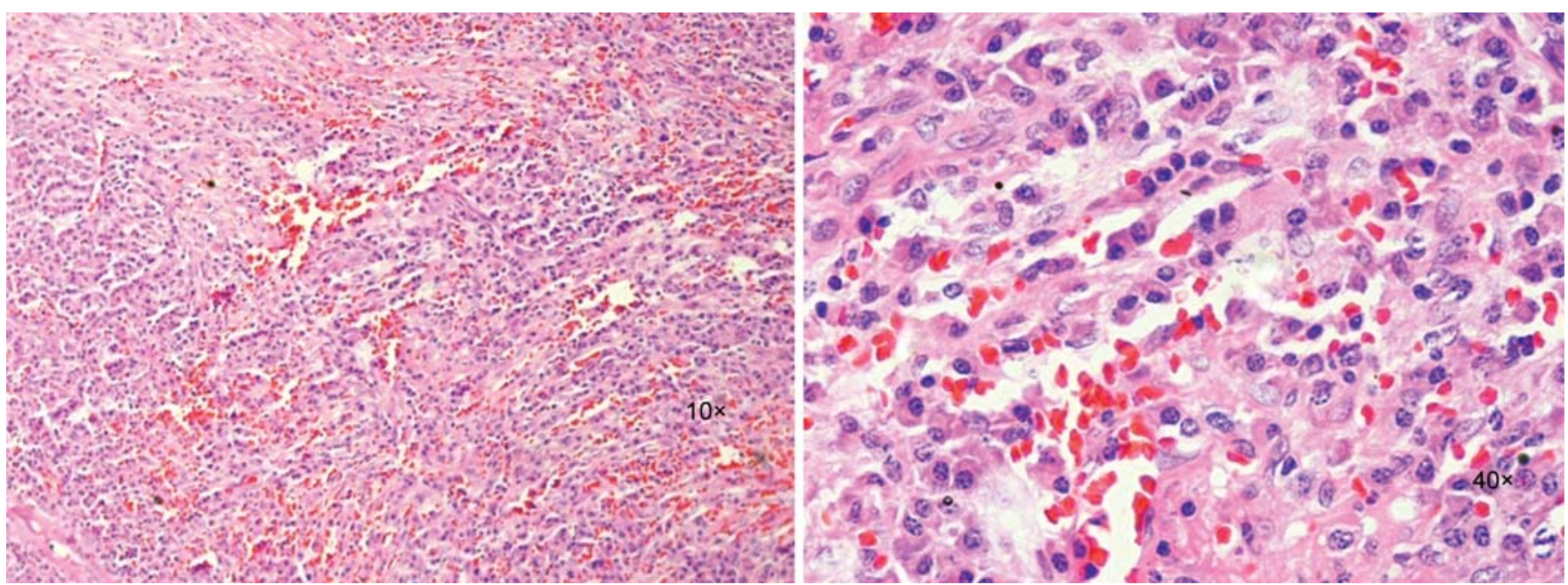

Fig. 2: Plasma cells, lymphocytes and spindle-shaped proliferating fibroblasts. The tumor was positive for vimentin and desmin, suggesting a myofibroblastic origin 


\section{REFERENCES}

1. Coffin CM, Watterson J, Priest JR, et al. Extrapulmonary inflammatory myofibroblastic tumor (inflammatory pseudotumor): A clinicopathologic and immunohistochemical study of 84 cases. A m J Surg Pathol 1995;19:859-72.

2. Ereno C, Lopez JI, Grande J, Santaolalla F, Bilbao FJ. Inflammatory myofibroblastic tumour of thelarynx. J Laryngol Otol 2001;115:856-58.

3. Pettinato G, M anivel J C, De R osa N, D ehner L P. I nflammatory myofibroblastic tumor (plasma cell granuloma): Clinicopathologic study of 20 cases with immunohistochemical and ultrastructural observations. A m J Clin Pathol 1990;94:538-46

4. W eiss SW . Histological typing of soft tissue tumors (2nd ed). B erlin: Springer-V erlag 1994:48.

5. Coffin CM, Fletcher J A I Inflammatory myofibroblastic tumor. In: Fletcher CDM, U nni KK, M ertens F (Eds). World Health Organization classification of tumours. Pathology and genetics of tumours of soft tissue and bone. Lyon: IARC Press 2002; 91-93.

6. Beck J C, Devaney K, W eatherly RA, et al. Pediatric myofibromatosis of the head and neck. A rch O tolaryngol Head Neck Surg 1999;125:39-44.

7. Baerg J, M urphy JJ, M agee J F. Fibromatoses: Clinical and pathological features suggestive of recurrence. J Pediatr Surg 1999;34:1112-14.

8. L awrence B, Perez-A tayde A, H ibbard M K, et al. TPM 3- A LK and TPM 4-ALK oncogenes in inflammatory myofibroblastic tumors. A m J Pathol 2000;157:377-84.

9. Coffin CM , Patel A, Perkins S, Elenitoba-J ohnson K S, Perlman $E, G$ riffin CA. ALK and $p 80$ expression and chromosomal rearrangements involving 2 p23 in inflammatory myofibroblastic tumor. M od Pathol 2001;14:569-76.

10. A rber DA, K amel OW, van de Rijn M, et al. Frequent presence of the Epstein-Barr virus in inflammatory pseudotumor. Hum Pathol 1995;26:1093-98.
11. Swamy BN, M cCulskey P, Nemet A, et al. Idiopathic orbital inflammatory syndrome: Clinical features and treatment outcomes. Br J Opthalmol 2007;91:1667-70.

12. K lein A M, Schoem SR, A Itman A, E isenfeld L. Inflammatory myofibroblastic tumor in the neonate: A case report. O tolaryngol Head N eck Surg 2003;128:145.

\section{ABOUT THE AUTHORS}

\section{Preetam}

Senior Resident, Department of Otorhinolaryngology and Head and Neck Surgery, All India Institute of M edical Sciences, New Delhi India

\section{Rajeev Kumar}

Pool Officer, Department of Otorhinolaryngology and H ead and N eck Surgery, A II India Institute of M edical Sciences, N ew Delhi, India

\section{Kapil Sikka}

Assistant Professor, Department of Otorhinolaryngology and Head and N eck Surgery, A II India Institute of M edical Sciences, New Delhi India

\section{Rakesh Kumar}

A ssociate Professor, D epartment of Otorhinolaryngology and Head and Neck Surgery, A II India Institute of M edical Sciences, N ew Delhi, India

Correspondence Address: Room N o. 4057, ENT Office, 4th Floor Teaching Block, All India Institute of M edical Sciences, A nsari Nagar New Delhi-110029, India, Phone: 09868397461, e-mail: winirk@ hotmail.com

\section{Prashant Durgapal}

Senior Resident, Department of Pathology, A II India Institute of Medical Sciences, N ew Delhi, India 